\title{
Characterizing Microbial Signatures on Sculptures and Paintings of Similar Provenance
}

\author{
Manolito G. Torralba ${ }^{1}$ (D) $\cdot$ Claire Kuelbs $^{1} \cdot$ Kelvin Jens Moncera $^{1} \cdot$ Rhonda Roby $^{2} \cdot$ Karen E. Nelson $^{1}$
}

Received: 10 December 2018 / Accepted: 17 March 2020 / Published online: 21 May 2020

(C) The Author(s) 2020

\begin{abstract}
The preservation of artwork challenges museums, collectors, and art enthusiasts. Currently, reducing moisture, adjusting the type of lighting, and preventing the formation of mold are primary methods to preserving and preventing deterioration. Other methods such as ones based in detailed knowledge of molecular biology such as microbial community characterization using polymerase chain reaction (PCR) and sequencing have yet to be explored. Such molecular biology approaches are essential to explore as some environmental bacteria are capable of oxidizing nonpolar chemical substances rich in hydrocarbons such as oil-based paints. Using 16S rDNA Illumina Sequencing, we demonstrate a novel finding that there are differing bacterial communities for artwork from roughly the same era when comparing paintings on wood, paintings on canvases, and sculptures made of stone and marble. We also demonstrate that there are specific genera such as Aeromonas known for having oxidase positive strains, present on paintings on wood and paintings on canvas that could potentially be responsible for deterioration and fading as such organisms produce water or hydrogen peroxide as a byproduct of cytochrome $\mathrm{c}$ oxidase activity. The advantages of these genomics-based approaches to characterizing the microbial population on deteriorating artwork provides immense potential by identifying potentially damaging species that may not be detected using conventional methods in addition to addressing challenges to identification, restoration, and preservation efforts.
\end{abstract}

Keywords Genomics $\cdot$ Sequencing $\cdot$ Microbiome $\cdot$ Microbial ecology $\cdot$ Artwork $\cdot$ Environmental microbiology

\section{Introduction}

Works of art, from the Renaissance period, for example have had an important influence in nearly all aspects of human creativity, innovation, and imagination. From inspiring architecture and design to influencing human interactions, artwork has become an integral part of society. From a financial perspective, art sales have grown into a multibillion dollar industry with total worldwide sales of over $\$ 63.8$ billion dollars in $2015,43 \%$ of which were in the USA alone [1]. The profitability of such an industry comes with its challenges, particularly with the restoration and preservation of damaged and/or aging artworks where restoration efforts for various sized

Manolito G. Torralba

mtorralb@jcvi.org

1 J. Craig Venter Institute, 4120 Capricorn Lane, La Jolla, CA 92037, USA

2 Alameda County Sheriff's Office, Crime Laboratory, 2901 Peralta Oaks Court, Oakland, CA 94605, USA individual paintings can range from US $\$ 1000$ to $\$ 15,000$ [2]. Some of the necessary equipment used for these efforts can multiply these costs, such as sophisticated $\mathrm{x}$-ray machines and infrared cameras costing $\$ 100,000$ each [2]. Additionally, authenticity in this industry is becoming more and more challenging as counterfeits today are more sophisticated [3, 4]. Restoration and preservation efforts are increasingly important to museums and art collectors as the value of artwork continues to $\operatorname{climb}([5,1])$.

Currently, most restoration and preservation efforts address physical and chemical aspects with minor emphasis on the effect of microorganisms when it comes to preservation ([5]). Limiting excess exposure to direct sunlight, heat sources, UV light, and moisture are all highly recommended [6]. The most common preservation and restoration effort regarding microorganisms is the preventing the formation of fungal colonies commonly observed as mold. Preventive measures against mold utilized by museums include monitoring humidity and reducing exposure to natural light and moisture $[6,7]$. Efforts to characterize microbial communities using thorough approaches such as genomics on artwork have yet to be thoroughly conducted. 
Initial studies using molecular biology techniques such as DGGE, Sanger sequencing, and culture-dependent approaches have shown that microorganisms belonging to three phyla, Actinobacteria, Proteobacteria, and Clostridia, are detected in deteriorating artwork and may be implicated in the rapid decay of fresco, concrete, marble, sandstone, and murals $[8,9,10,11,12,13]$. Paintings provide a unique substrate for microbes to grow as paints often contain a variety of biodegradable organic and inorganic compounds that can be exploited by microorganisms as a source of nutrients $[14$, $15,10,16,17]$. Additionally, the substrate material that is often used for paintings can also provide biodegradable material such as animal or plant glues used for support, and cellulose in paper, canvas, and wood [14]. It is clear that these types of studies are gaining importance as we now know that specific bacteria are known to degrade environmental hydrocarbons commonly found in oil-based paints as well as produce various acids as metabolic end products $[18,19]$. Though it is tempting to speculate that these bacterial processes are likely associated with the rapid decay of artwork, it is premature since studies focusing on entire bacterial communities and potential associated metabolic processes using next generation sequencing have yet to be conducted prior to our study.

In order to fully characterize the effect that microbial communities have on degradation of aging artwork, henceforth referred to as biodegradation, comprehensive genomics approaches are suggested as sequencing costs have dramatically reduced and large datasets on this sample type will provide a novel perspective on identifying entire communities. With the use of Illumina sequencing and conserved genetic markers such as 16S rRNA, we have been able to characterize entire microbial communities on various specimens of aging artwork. Our study characterizes the microbial communities on stone/marble, wood, and canvas from a private collection near Florence in the Tuscany region of Italy. Though prior studies have attempted to characterize the microbial composition associated with artwork decay, our results summarize the first large scale genomics-based study to understand the microbial communities associated with aging artwork.

\section{Experimental Procedures}

\section{Sampling of Artwork}

Several pieces from a private art collection in the Tuscany region of Italy were used as samples for our study (Fig. 1 and Table 1). The private collection was stored in an approximate 2000 sq.ft. area with low lighting and an ambient cool environment. While we have the assurance of the owner of the private collection that the works have been handled little in recent decades and never restored, we did not obtain documentation of the provenance of the works. Five of the six works are in a Renaissance style, although it is possible that they may have been created later. One piece is in a Roman style but may also be from the Renaissance or later. Recent history of ownership suggests the works are at least a couple of centuries old, if not much older. For our proof-of-concept study, the key was to have access to a variety of older artwork substrates that had not been aggressively cleaned.

The sampled artwork varied in substrates that ranged from paintings on wood, paintings on canvas, and stone and marble sculptures. The samples were collected using sterile techniques in preparation for DNA extraction, 16S PCR and Illumina Sequencing. Individually wrapped sterile swabs (Ref 25-806-1PD, Puritan Medical Products, Guilford, ME) were used to swab various sections on each art piece with approximately 10-12 gentle swipes per collection of an approximate $3-\mathrm{cm}^{2}$ area. The sample swab tips were transferred to $1.5-\mathrm{mL}$ sterile microcentrifuge tubes. A total of $500 \mu \mathrm{L} 1 \mathrm{X}$ TE buffer was also added to each tube containing a swab tip. Each art piece was sampled in three distinct areas with at least $3 \mathrm{~cm}$ between each sampled section. Negative controls were collected by opening swab packages in the same location as the collected swab samples and immediately placing swabs into collection tubes with $1 \mathrm{X}$ TE buffer. A summary of the samples is outlined in Table 1 and shown in Fig. 1.

\section{DNA Extraction, 16S PCR, and Sequencing}

Each sample swab was treated with $700 \mu \mathrm{L}$ lysis buffer (20 mM Tris-Cl, pH 8.0, 2 mM EDTA, 1.2\% Triton X-100) and incubated at $75{ }^{\circ} \mathrm{C}$ for $10 \mathrm{~min}$. Samples were then cooled to room temperature, treated with $200 \mathrm{mg} / \mathrm{mL}$ lysozyme (Sigma/Aldrich, St Louis, MO) and incubated at $37^{\circ} \mathrm{C}$ for $60 \mathrm{~min}$, followed by adding $100 \mu \mathrm{L} \mathrm{10 \%} \mathrm{SDS} \mathrm{and} 20 \mathrm{mg} /$ $\mathrm{mL}$ proteinase $\mathrm{K}$ (Life Technologies, Carlsbad, CA) and incubated at $55^{\circ} \mathrm{C}$ overnight. DNA was twice extracted from the lysate by an equal volume of phenol chloroform isoamyl alcohol followed by ethanol precipitation. Extracted DNA was suspended in $1 \mathrm{X}$ TE buffer. Residual PCR inhibitors were removed using the MOBio Powerclean kit (MOBio Labs, Carlsbad, CA) using manufacturer's specifications. DNA was quantified using fluorometric methods (SybrGold, ThermoFisher, Waltham, MA) prior to downstream applications. The V4 region of the $16 \mathrm{~s}$ rRNA was amplified using adaptor and barcode-ligated specific primers [20, 21, 22]. Samples were sequenced using MiSeq Reagent Kit v2 chemistry, 500 cycles dual index $2 \times 250$ bp format (Illumina Inc., La Jolla, CA) according to manufacturer's specifications.

\section{Quality Control and Processing of DNA Sequences}

DNA sequences were processed to ensure that only quality sequences were applied to the mothur pipeline [23]. Stringent settings were maintained to ensure that there were no barcode 
Fig. 1 Photo summary of the various artworks sampled for this study. Circles indicate swabbed areas on each sample artwork. Photos not shown include: FL007B and FL002B

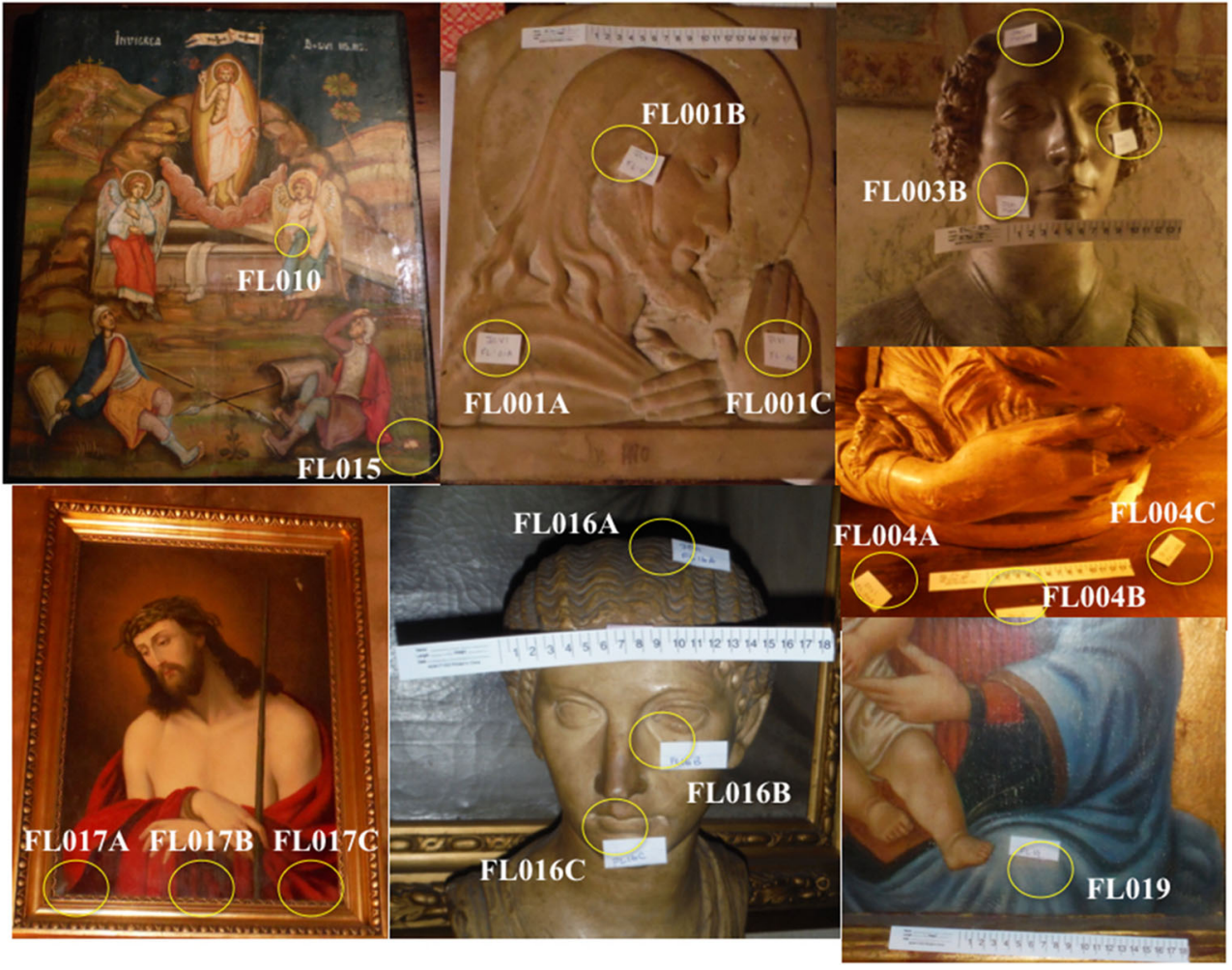

mismatches among the demultiplexed reads. Sequence filtering was used by applying the screen.seqs function of mothur to remove all sequences shorter than $220 \mathrm{bp}$. Additional QC steps were implemented, and the sequences were aligned against the SILVA database to confirm the orientation of noise-filtered sequences and to ensure the correct positioning of the amplified and sequenced variable region reads [24]. The sequences passing QC were then checked for chimeras and classified taxonomically using mothur, eliminating hits matching mitochondria, chloroplast, archaea, eukaryote, and other unknown sequences, to avoid noise from the data [23]. Archaea was removed primarily due to poor taxonomic classification below the Phylum level using the SILVA database. Sequence reads were then clustered at various taxonomic levels including $97 \%$ rRNA sequence similarity defined as operational taxonomic units (OTU).

\section{Data Analysis}

Species, genus, and phyla count tables of $16 \mathrm{~S}$ rRNA reads from the mothur output files were used for all subsequent statistical analyses in the $R$ statistical environment [25]. The VEGAN and APE $R$ packages were used for all statistics calculations, multivariate analyses, including Bray-Curtis dissimilarity, PCoA, PERMANOVA, ANOSIM, and sample clustering $[26,27]$. The mothur open-source software was also used to calculate Shannon and CHAO diversity indices to calculate species richness, and evenness. Kruskal-Wallis testing was used as a non-parametric approach to determine the statistical significance of the varying levels of abundance at the genus level between the samples. $P$ values $<0.05$ were considered significant in these calculations.

\section{Results}

A total of 287,881 sequence reads from the artwork post filtering and quality control (QC) were generated; each sample swab averaged 7,500 sequence reads. As expected, several samples did not yield a significant number of sequence reads. These samples are suspected of having low microbial biomass upon collection. Samples with less than 2000 sequence reads, including the negative controls, were excluded in the analysis as this would have limited coverage and would not represent the microbial community as the other samples with higher coverage would. Sequences are publicly available in the National Center for Biotechnology Information (NCBI) Short Read Archive (SRA) under accession PRJNA505184.

\section{Microbial Composition Among Substrates: Wood, Canvas, and Marble}

Upon review of the $16 \mathrm{~S}$ data, the microbial populations were easily discernable between the different types of substrates sampled. Wood was primarily composed of unclassified 
Table 1 Summary of samples collected and processed. All samples with the exception of FL019 were stored in the same room

\begin{tabular}{lllll}
\hline Sample ID & Data collected & Collection location & Substrate & Comment/description \\
\hline FL001A & $11 / 30 / 15$ & Tuscany, Italy & Marble/stone & Pink marble sculpture-deep swab of shoulder area \\
FL001B & $11 / 30 / 15$ & Tuscany, Italy & Marble/stone & Pink marble sculpture-deep swab of temple and ear \\
FL001C & $11 / 30 / 15$ & Tuscany, Italy & Marble/stone & Pink marble sculpture-deep swab of hand \\
FL002B & $11 / 30 / 15$ & Tuscany, Italy & Marble/stone & Deep swab of shelf floor \\
FL003B & $11 / 30 / 15$ & Tuscany, Italy & Marble/stone & Renaissance-style bust-dining room-deep swab of left cheek \\
FL016A & $12 / 1 / 15$ & Tuscany, Italy & Marble/stone & Roman-style bust-deep swab of hair \\
FL004A & $11 / 30 / 15$ & Tuscany, Italy & Wood & Deep swab of wood cabinet \\
FL004B & $11 / 30 / 15$ & Tuscany, Italy & Wood & Deep swab of wood cabinet \\
FL004B & $11 / 30 / 15$ & Tuscany, Italy & Wood & Deep swab of wood cabinet \\
FL007B & $12 / 1 / 15$ & University of Firenze & Wood & Ascension-light swabbing of black paint-painted side \\
FL010 & $12 / 1 / 15$ & University of Firenze & Wood & Ascension-deep swirl \\
FL015 & $12 / 1 / 15$ & Tuscany, Italy & Wood & Ascension-deep swab of large broken patch of exposed wood \\
FL017A & $12 / 1 / 15$ & Tuscany, Italy & Canvas & Christ painting-deep swab bottom left \\
FL017B & $12 / 1 / 15$ & Tuscany, Italy & Canvas & Christ painting-deep swab bottom center \\
FL017C & $12 / 1 / 15$ & Tuscany, Italy & Canvas & Christ painting-deep swab bottom right \\
FL019 & $12 / 1 / 15$ & Tuscany, Italy & Canvas & Madonna painting deep swab over green spots possible biofilm formation
\end{tabular}

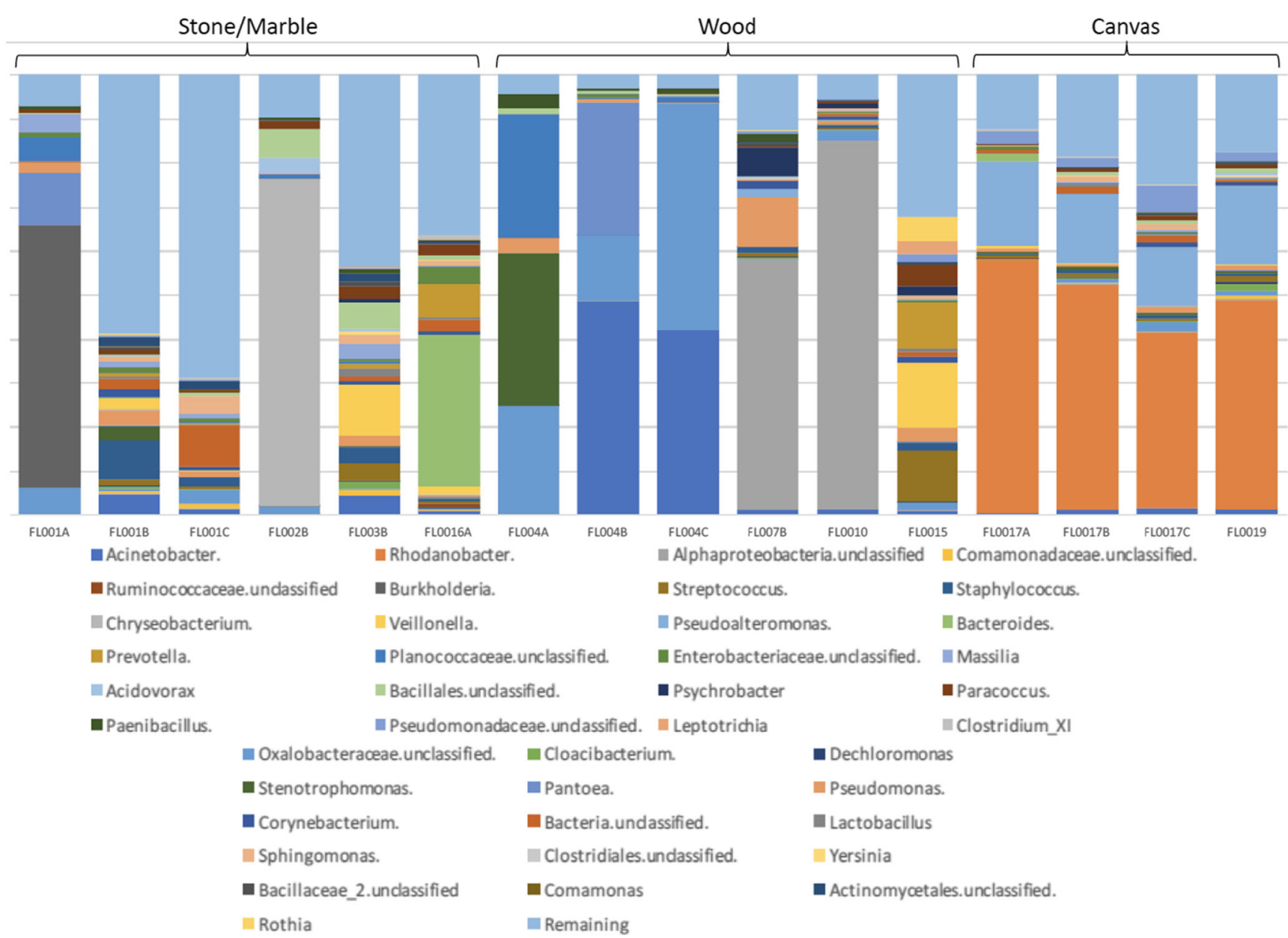

Fig. 2 Stacked bar chart of the top 40 most abundant genera in the dataset. Sample types are grouped to show differences in taxonomy between substrate types as well as variation within sample types 
Shannon Diversity Indices by Substrate

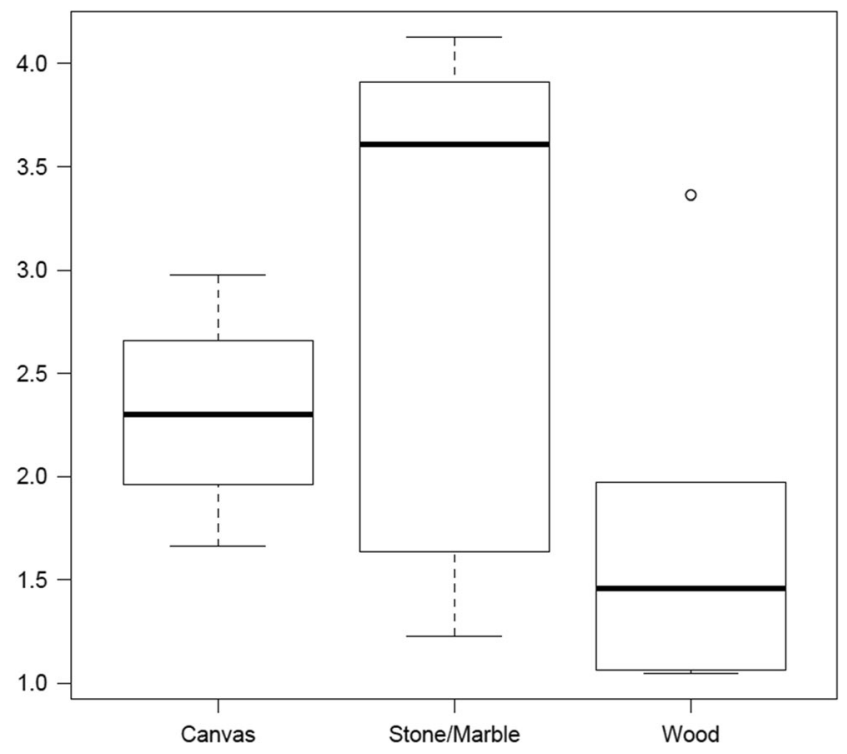

Fig. 3 Shannon diversity index comparison between substrates to indicate the variation in microbial composition and richness between substrate types. Stone/marble appears to have the most diverse community found in our sample types

Oxalobacteraceae and Acinetobacter (FL004A, B, and C) or Alphaproteobacteria (FL007B and FL0010). Paintings on canvas were primarily composed of Rhodanobacter and Pseudoalteromonas. Samples collected from paintings on canvas also showed the most consistency of which genera were most abundant regardless of the sample location or painting sampled (Fig. 2). The most abundant genera in stone/ marble samples were unclassified Oxalobacteraceae, Burkholderia, Staphylococcus, Pseudomonas, Bacteroidetes, and Chryseobacterium. The microbial composition in stone/ marble also varied more than wood and canvas, where swabs taken at different locations on the same artwork varied in microbial composition (Fig. 2). Furthermore, the stone/ marble samples also had a higher degree of diversity when compared with canvas and wood samples (Fig. 3). Principal coordinates analyses indicate that the sample swabs can be distinguished according to the sample and substrate from which they were collected (Fig. 4).

\section{Microbial Population Diversity Decreases on Non-painted Wood when Compared with Painted Wood}

Though there were some consistent results between sample swabs collected from within the same painting, there were differences in the microbial composition when comparing the ascension painting swabs (all from the same painting: FL007, FL010, and FL015) as compared with samples collected from a non-painted wood cabinet (FL004A-C) stored in the same vicinity. Non-painted wood sample swabs FL004A, FL004B, and FL004C were mostly abundant in Acinetobacter and unclassified Oxalobacteraceae. Painted wood sample swabs FL007 and FL010 were abundant in mostly unclassified Alphaproteobacteria, whereas FL015, also from the same painting, was composed of mostly Streptococcus, Veillonella, Prevotella, Paracoccus, and Rothia. Shannon diversity index calculations indicate that there is a higher level of diversity in microbial composition of painted wood when compared with non-painted wood (Fig. 5).
Fig. 4 Principal coordinates analysis of sample swabs. Sample clustering is evident by sample type. Sample swabs collected from wood and stone were more similar to each other when compared to sample swabs collected from canvas

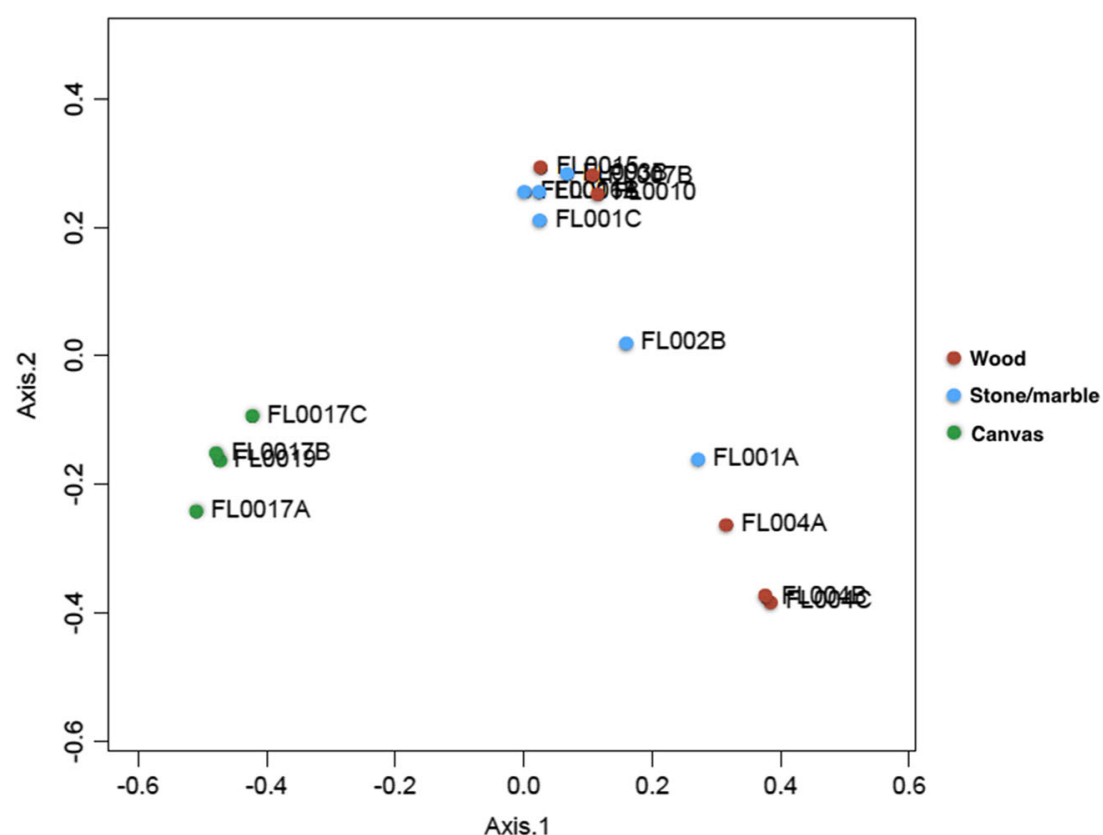


Shannon Diversity Index Painted Wood vs Non Painted Wood

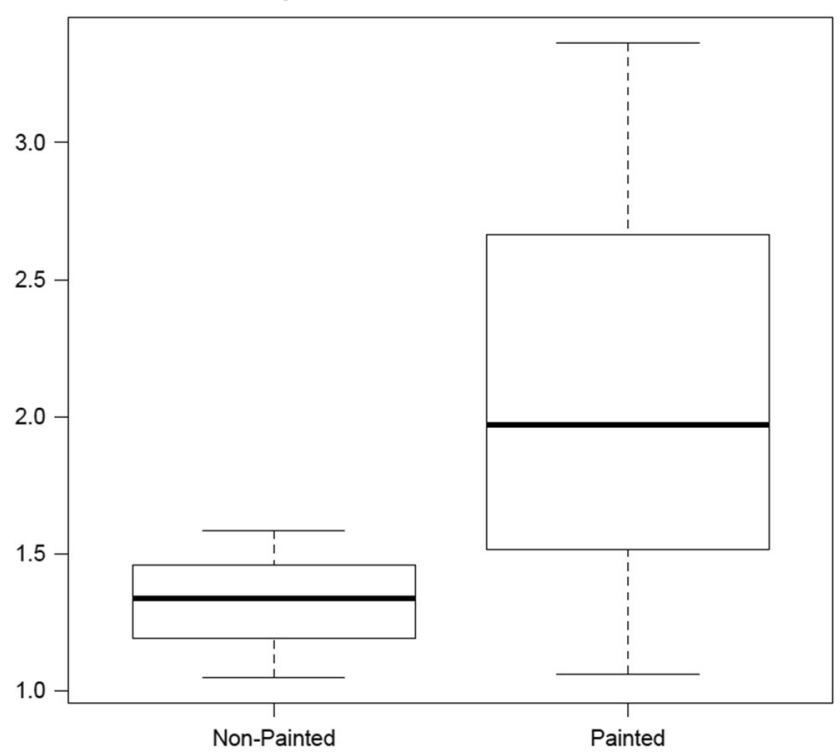

Fig. 5 Shannon diversity index comparison between painted and nonpainted wood. Larger overall spread of diversity indices summarizes the more complex communities in painted wood versus non-painted wood

\section{Oxidase Positive Genera Present on Paintings on Canvas and Paintings on Wood}

We were able to detect the presence of five genera known to contain oxidase positive species in our dataset. Pseudomonas was detected in all samples regardless of substrate, and Campylobacter was detected at low frequencies in stone/ marble and painted wood only. Neisseria and Vibrio were detected in higher abundance on painted wood when compared with stone/marble. Though Aeromonas was present on both painted wood and stone/marble, these genera was identified in higher abundance on painted wood when compared with stone/marble (Fig. 6).

\section{Discussion}

The microbial signatures detected on the various pieces of artwork in our study provide us with a novel approach to not only characterizing the microbial composition on aging artwork but also insight into identification, restoration, and preservation efforts. We were able to easily distinguish the different sample types according to individual microbial biosignatures despite being stored within the same home in the private collection. The most interesting find in our study would be the presence of genera known to contain oxidase positive species found primarily on painted wood and canvas surfaces. This is of great interest to preservation efforts as members of oxidase positive species are capable of using oxygen for energy production and producing water or hydrogen peroxide as a byproduct. Such byproducts are likely to influence the presence of mold and the overall rate of deterioration. Additionally, oxidase positive bacteria have been known to be capable of metabolizing environmental contaminants rich in hydrocarbons, which are common in oil-based paints [28, 29]. Pseudomonas was identified in all sample types which was to be expected since this genus is a common environmental aerobe with diverse metabolic capabilities allowing various species to survive in different environments. The higher abundance of genera known to contain oxidase positive species; Neisseria, Vibrio, and Aeromonas in painted samples was of particular interest as they were specifically found on painted wood rather than non-painted wood. Currently, we are unable to speculate as to why this is the case until additional studies with higher numbers of samples and deeper sequencing are conducted for comparative analysis.

The varying surface types are likely to influence the microbial composition as all three substrates are different from each other when it comes to porosity, thickness, density, depth of crevices, and ability to retain moisture. When comparing the substrate types, it was interesting to see that the stone/marble

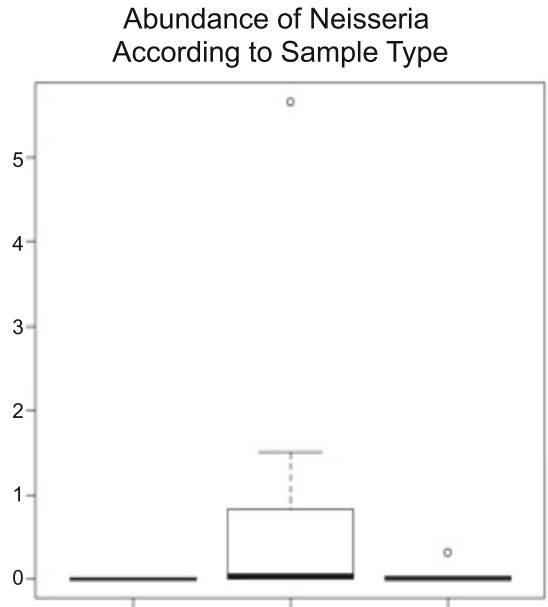

Non-Painted
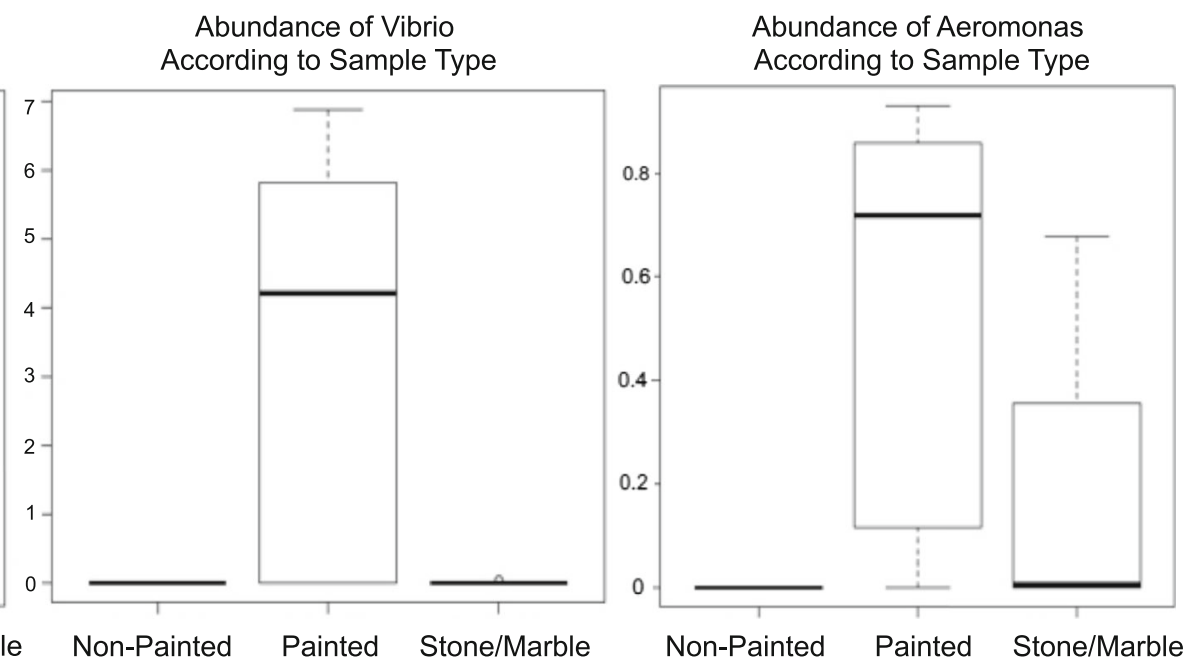

Fig. 6 Comparing the varying abundances of specific genera in painted wood, non-painted wood, and stone/marble known to have various species capable of oxidase positive activity 
samples showed greater microbial diversity when compared with wood and canvas. This is likely due to the porous nature of stone and marble which is harboring additional organisms and potentially moisture and nutrients, along with the likelihood of biofilm formation. The low microbial diversity observed in canvas and wood are likely the result of lack of nutrients as the primary source of energy would be the oil-based paint that few organisms can metabolize. Canvas and wood are also providing the microbial community additional nutrients as both substrates are high in cellulose and organic matter which are likely influencing the taxonomy of the populations found on these surfaces. Future studies should evaluate the metabolic process of highly abundant bacteria on wood and canvas surfaces.

Though our sample size is low, the novelty of our study has provided the art and scientific communities with evidence that microbial signatures are capable of differentiating artwork according to their substrate. In addition, we can also speculate that the origin of artwork can be recognized using similar techniques which would be exceedingly useful in confirming authenticity. In an unrelated study, we demonstrated that microbial signatures and patterns are geographically distinguishable when comparing the microbial signatures in human hairs collected near Washington D.C., and human hairs collected in San Diego, CA [30]. This approach can potentially be used to distinguish artwork from one location to another thus supporting any efforts of confirming authenticity and identifying any counterfeits that appear to originate in a different geographical location. Such approaches are well-utilized as many projects have focused on characterizing the microbial composition in regard to environmental and clinical studies, but has yet to be applied to this degree in regard to characterizing artwork [31, 32].

Enormous potential in preservation and restoration of artwork can also be achieved with these approaches as we have demonstrated that we are capable of identifying entire communities of bacteria present on various pieces of aging artwork. Future studies would benefit from working with samples whose authorship, ownership, and care are well-documented, although documentation about care of works of art (e.g., whether and how they were cleaned) seems rare before the midtwentieth century. As we are currently proficient in identifying entire microbial communities on different surfaces, we provide a useful foundation for improving conservation and identification efforts. The next steps in this endeavor would be to characterize the metabolic processes that these communities use thus providing a clear understanding of microbial composition and function. Additional studies that incorporate genomics approaches to deteriorating artwork are necessary to fully characterize the microbial composition down to species and strain level taxonomy. Metagenomics and metatranscriptomics approaches will confirm the presence of metabolic genes responsible for oxidase activity, hydrocarbon metabolism, and upregulation of such processes respectively. Of particular interest would be presence and activity of oil degrading enzymes [28]. Such approaches will lead to fully understanding which organism(s) are responsible for the rapid decay of artwork while potentially using this information to target these organisms to prevent degradation. Focusing on reducing the abundance of such destructive organisms has great potential in preserving and restoring important pieces of human history.

Acknowledgements The authors extend their sincere appreciation to the Richard Lounsbery Foundation and its Vice Chair, Dr. Jesse Ausubel, for supporting the various aspects of this research and for providing the significant networking opportunities with the scientists and collectors in Florence and Tuscany, Italy. We would also like to thank Dr David Caramelli of the University of Florence for the use of his lab facility for sample collection.

\section{Compliance with Ethical Standards}

Conflict of Interest The authors declare that they have no conflict of interest.

Open Access This article is licensed under a Creative Commons Attribution 4.0 International License, which permits use, sharing, adaptation, distribution and reproduction in any medium or format, as long as you give appropriate credit to the original author(s) and the source, provide a link to the Creative Commons licence, and indicate if changes were made. The images or other third party material in this article are included in the article's Creative Commons licence, unless indicated otherwise in a credit line to the material. If material is not included in the article's Creative Commons licence and your intended use is not permitted by statutory regulation or exceeds the permitted use, you will need to obtain permission directly from the copyright holder. To view a copy of this licence, visit http://creativecommons.org/licenses/by/4.0/.

\section{References}

1. Kinsella E (2016). What does TEFAF 2016 art market report tell us about the global art trade? Retrieved 1/4/2017, from https://news. artnet.com/market/tefaf-2016-art-market-report-443615

2. Kaplon M (2016). The cost of conservation and restoration. Retrieved 1/4/2017, from http://artbusinessnews.com/2015/12/thecost-of-conservation-and-restoration/

3. Blair E (2014). 'Art \& Craft' explores how one forger duped more than 45 museums. retrieved 3/14/2017, 2017, from http://www.npr. org/2014/09/27/351738720/art-craft-explores-how-one-forgerduped-more-than-45-museums

4. Spiel RE (2000) Art theft and forgery investigation: the complete field manual. Charles C Thomas Publisher, Springfield

5. Larson J.H., Frank Zuccari, Jerry C. Podany, Donald W. Insall, Anne Lee Rosenthal and Brommelle N. S.. (2016). Art conservation and restoration. Encyclopædia Britannica Retrieved 2/22/2017, 2017, from https://www.britannica.com/art/art-conservation-andrestoration

6. Institute, S. M. C. (2013, Museum Conservation Institute: taking care. retrieved 2/22/2017, 2017, from http://www.si.edu/mci/ english/learn more/taking care/mnm.html

7. Mecklenburg M F, Tumosa C S. (2003). Resolving the conflict between building preservation and the proper temperature and relative humidity requirements of collections. Retrieved 2/22/2017, 
2017, from http://www.si.edu/mci/downloads/reports/ resolvingconflict.pdf

8. Abdelhafez AAM, El-Wekeel FM, Ramadan EM, Abed-Allah AA (2012) Microbial deterioration of archaeological marble: identification and treatment. Ann Agric Sci 57(2):137-144

9. Kane MD, Poulsen LK, Stahl DA (1993) Monitoring the enrichment and isolation of sulfate-reducing bacteria by using oligonucleotide hybridization probes designed from environmentally derived 16S rRNA sequences. Appl Environ Microbiol 59(3):682-686

10. Lopez-Miras M, Pinar G, Romero-Noguera J, Bolivar-Galiano FC, Ettenauer J, Sterflinger K, Martin-Sanchez I (2013) Microbial communities adhering to the obverse and reverse sides of an oil painting on canvas: identification and evaluation of their biodegradative potential. Aerobiologia (Bologna) 29(2):301-314

11. Ma Y, Zhang H, Du Y, Tian T, Xiang T, Liu X, Wu F, An L, Wang W, Gu JD, Feng H (2015) The community distribution of bacteria and fungi on ancient wall paintings of the Mogao Grottoes. Sci Rep $5: 7752$

12. Mansch R, Bock E (1998) Biodeterioration of natural stone with special reference to nitrifying bacteria. Biodegradation 9(1):47-64

13. Rolleke S, Muyzer G, Wawer C, Wanner G, Lubitz W (1996) Identification of bacteria in a biodegraded wall painting by denaturing gradient gel electrophoresis of PCR-amplified gene fragments coding for 16S rRNA. Appl Environ Microbiol 62(6): 2059-2065

14. Ciferri O (1999) Microbial degradation of paintings. Appl Environ Microbiol 65(3):879-885

15. Douma $M(2008)$. Pigments through the ages. retrieved $2 / 22 / 2017$, 2017, from http://www.webexhibits.org/pigments/intro/history.html

16. Lopez-Miras Mdel M, Martin-Sanchez I, Yebra-Rodriguez A, Romero-Noguera J, Bolivar-Galiano F, Ettenauer J, Sterflinger K, Pinar G (2013) Contribution of the microbial communities detected on an oil painting on canvas to its biodeterioration. PLoS One 8(11):e80198

17. Stoye D, Funke W, Hoppe L, Hasselkus J, Curtis LG, Hoehne K, Zech H-J, Heiling P, Yamabe M, Dören K, Schupp H, Küchenmeister R, Schmitthenner M, Kremer W, Wieczorrek W, Gempeler H, Schneider W, White JW, Short AG, Blank WJ, Calbo LJ, Plath D, Wagner F, Haller W, Rödder K-M, Streitberger H-J, Urbano E, Laible R, Meyer BD, Bagda E, Waite FA, Philips M, Köhler K, Simmendinger P, Roelle W, Scholz W, Valet A, Slongo M, Molz T, Hiller R, Thomer KW, Vogel K, Schernau U, Hüser B, Brandt A, Milne A, Weyers H, Plehn W, Lentze H-A (2000) Paints and coatings. Ullmann's encyclopedia of industrial chemistry. Wiley-VCH Verlag GmbH \& Co, KGaA

18. Jurtshuk Jr P (1996) Medical Microbiology4th edn. University of Texas Medical Branch at Galveston, Galveston (TX)

19. Leahy JG, Colwell RR (1990) Microbial degradation of hydrocarbons in the environment. Microbiol Rev 54(3):305-315
20. Caporaso JG, Lauber CL, Walters WA, Berg-Lyons D, Lozupone CA, Turnbaugh PJ, Fierer N, Knight R (2011) Global patterns of 16S rRNA diversity at a depth of millions of sequences per sample. Proc Natl Acad Sci U S A 108(Suppl 1):4516-4522

21. Haas BJ, Gevers D, Earl AM, Feldgarden M, Ward DV, Giannoukos G, Ciulla D, Tabbaa D, Highlander SK, Sodergren E, Methe B, DeSantis TZ, Petrosino JF, Knight R, Birren BW (2011) Chimeric 16S rRNA sequence formation and detection in Sanger and 454-pyrosequenced PCR amplicons. Genome Res 21(3):494-504

22. Kozich JJ, Westcott SL, Baxter NT, Highlander SK, Schloss PD (2013) Development of a dual-index sequencing strategy and curation pipeline for analyzing amplicon sequence data on the MiSeq Illumina sequencing platform. Appl Environ Microbiol 79(17):5112-5120

23. Schloss PD, Westcott SL, Ryabin T, Hall JR, Hartmann M, Hollister EB, Lesniewski RA, Oakley BB, Parks DH, Robinson CJ, Sahl JW, Stres B, Thallinger GG, Van Horn DJ, Weber CF (2009) Introducing mothur: open-source, platform-independent, community-supported software for describing and comparing microbial communities. Appl Environ Microbiol 75(23):7537-7541

24. Pruesse E, Quast C, Knittel K, Fuchs BM, Ludwig W, Peplies J, Glöckner FO (2007) SILVA: a comprehensive online resource for quality checked and aligned ribosomal RNA sequence data compatible with ARB. Nucleic Acids Res 35(21):7188-7196

25. Team RC (2015) R: a language and environment for statistical computing. R Foundation for Statistical Computing, Vienna

26. Jari Oksanen F G B, Roeland Kindt, Pierre Legendre, Peter R. Minchin, O'Hara R B, Gavin L Simpson, Peter Solymos, Henry M, Stevens H and Helene Wagner. (2015). Vegan: community ecology package. R package version 2.3-0. 2016, from http:// CRAN.R-project.org/package $=$ vegan

27. Paradis E, Claude J, Strimmer K (2004) APE: analyses of phylogenetics and evolution in R language. Bioinformatics 20(2):289-290

28. Yan S, Wang Q, Qu L, Li C (2013) Characterization of oildegrading bacteria from oil-contaminated soil and activity of their enzymes. Biotechnol Biotechnol Equip 27(4):3932-3938

29. Zhuang WQ, Tay JH, Maszenan AM, Krumholz LR, Tay ST (2003) Importance of gram-positive naphthalene-degrading bacteria in oil-contaminated tropical marine sediments. Lett Appl Microbiol 36(4):251-257

30. Brinkac L, Clarke TH, Singh H, Greco C, Gomez A, Torralba MG, Frank B, Nelson KE (2018) Spatial and environmental variation of the human hair microbiota. Sci Rep 8(1):9017

31. Gilbert J Meyer F (2012). Modeling the earth microbiome. Microbe Magazine

32. Gilbert JA, Jansson JK, Knight R (2014) The earth microbiome project: successes and aspirations. BMC Biol. 12(1):69 